\title{
Antagonist muscle activity during rapid arm movements: central versus proprioceptive influences ${ }^{1}$
}

\author{
R O N A L D W. A N G E L \\ From the Department of Neurology, Veterans Administration Hospital, Palo Alto, and Stanford \\ University School of Medicine, Stanford, California, USA
}

SUMMARY Seven normal subjects were instructed to adduct the arm as fast as possible. On some trials the movement was prevented mechanically. For each movement or attempted movement, the EMG response in the antagonist muscle was measured. On trials in which no movement occurred, the responses were significantly smaller than those obtained during free, ballistic movement. The results demonstrate the role of proprioceptive influences on the contraction of the antagonist muscle.

The EMG activity associated with voluntary movement of the upper limb was first recorded more than 50 years ago (Wachholder and Altenburger, 1926a,b; Wachholder, 1928). The original records show a characteristic EMG pattern which has been confirmed in several recent studies (Bizzi et al., 1971; Garland and Angel, 1971; Terzuolo et al., 1973; Angel, 1974; Hallett et al., 1975). In the half century since these records were published, much has been learned about the spinal and cerebral mechanisms controlling movement, but the normal EMG pattern is still poorly understood.

One question that remains unsettled is the relative importance of central versus peripheral factors in producing the normal pattern. Recent workers have found evidence that the initial volleys of EMG activity in the agonist and antagonist muscles are influenced relatively little by events at the periphery (Hallett et al., 1975). Hence, they propose that the first part of the normal, triphasic EMG pattern is preprogrammed (Hallett et al., 1976). The present study was designed to test this hypothesis.

\section{Methods}

Seven normal subjects (six males and one female ranging from 21 to 59 years of age) were studied.

'Supported by the Medical Research Service of the Veterans Administration.

Address for reprint requests: Dr R. W. Angel, Veterans Administration Hospital, Department of Neurology, 3801 Miranda Avenue, Palo Alto, California 94304, USA.

Accepted 13 January 1977
Muscle action potentials were recorded by means of Beckman skin electrodes, used with Beckman electrode paste and adhesive collars. Two electrodes were fastened over the posterior fibres of the right deltoid muscle, one just below the acromion and the other about $50 \mathrm{~mm}$ medially. Another pair of electrodes was fastened over the right pectoralis major. The electromyograms (EMGs) were processed by an averaging filter which displayed at each instant the sum of all EMG activity during the preceding $94 \mathrm{~ms}$ (Garland et al., 1972).

For each test, the subject was seated grasping the lower end of a $750 \mathrm{~mm}$ aluminium rod which was suspended vertically at arm's length anterior to the right shoulder. The upper end of this rod was coupled to a shaft which rotated as the subject moved the hand to the left or right. Transducers produced voltages proportional to the angular position and the velocity of the shaft.

For each trial, the assigned task was to swing the hand to the left over a distance of $150 \mathrm{~mm}$, as indicated by marks on a horizontal tape. The subject was instructed to move the hand as rapidly as possible. In this movement, the pectoral muscles are agonists, and the posterior portion of the deltoid is an antagonist.

After 20 to 25 movements had been recorded, the lower end of the rod was attached to a nylon cord which extended horizontally to the right. The other end of the cord was held against an electromagnet by a steel plate. The magnet was clamped in place, so that the rod could not be pulled to the left while the magnet was energised. 
On some of the subsequent trials, the current was turned off at the time of the command to move, so that there was no resistance to hand movement. On other trials, the current was not turned off, and leftward movement was prevented by the nylon cord.

Before each movement (or attempted movement) the subject was not told whether the cord would be released or not. He was instructed to make a standard $150 \mathrm{~mm}$ move, ignoring the possibility that movement would be checked on some trials. The blocked and unblocked conditions were alternated randomly until at least 20 trials of each kind were recorded.

Signals representing the position and velocity of the recording handle, along with the 'raw' and filtered EMGs, were displayed on paper by means of a Grass Model 7 polygraph. Measurements were taken from the ink-written records. The amplitude of each response from deltoid muscle (the antagonist) was measured as the distance from baseline to peak of the filtered EMG curve.

Three sets of measurements were obtained for each subject: (a) the initial 20 to 25 movements, (b) the unblocked movements during the second run, and (c) the blocked movements during the second run. The chief point of interest was whether or not the antagonist EMG responses were significantly different in sets (b) and (c). If the triphasic response were entirely preprogrammed, no difference would be expected.

\section{Results}

Figures 1 and 2 compare a free movement with one in which movement was blocked mechanically. The amplitude of the antagonist EMG response is noted to be smaller on the blocked move.

The Table shows the data obtained from all seven subjects. In each case the mean amplitude of the antagonist response is noted to be smaller during the blocked moves than during the unblocked, all differences being significant at the 0.01 level by Student's $t$ test.

For each subject, the average EMG obtained during blocked moves was some fraction of the mean for unblocked moves. The mean ratio was 0.44 with a standard deviation of 0.11 .

A comparison of the initial free moves (set a) with the free moves on the second run (set b) showed no difference in five of the seven subjects. In the other two cases, the antagonist did not fire so strongly on the trials when there was a 0.5 probability of encountering the block. For these two, the expectation of encountering the block evidently caused a reduction of EMG activity,

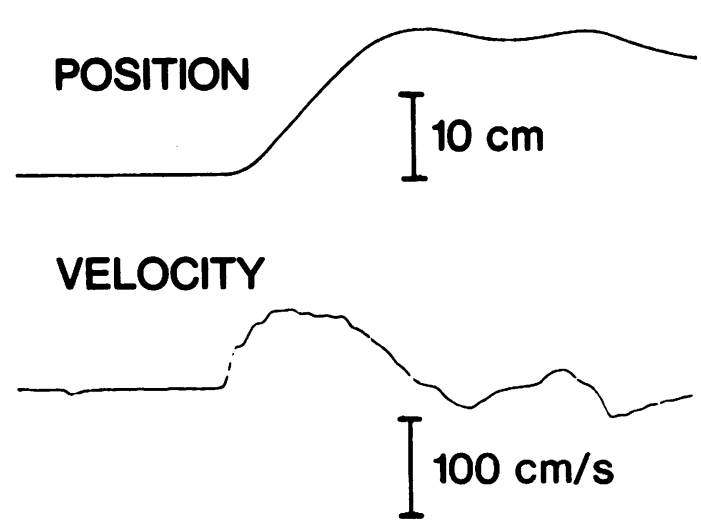

\section{FILTERED EMG}
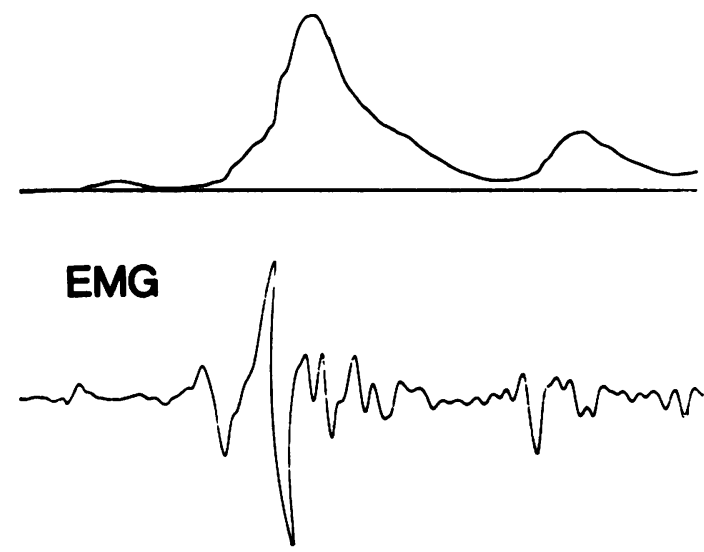

Fig. 1 Voluntary movement of right arm. Upward deflexions of position and velocity curves indicate movement of arm toward left (adduction). EMG from posterior deltoid (antagonist) muscle shows burst of activity during movement. Duration of entire trace equals one second.

even on trials where the block did not occur. The EMG response of the pectoral (agonist) muscles was not measured, but its amplitude did not appear to be changed by the unexpected mechanical block.

\section{Discussion}

During rapid movement of an extremity, the initial contraction of the agonist muscle is followed immediately by contraction of the antagonist. The function of the latter is obvious: it provides a braking force that decelerates the limb and brings it to rest at the desired position. The 
POSITION

\section{$\lceil 10 \mathrm{~cm}$}

\section{VELOCITY}

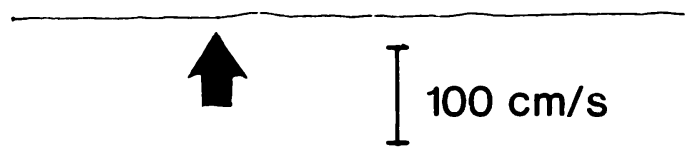

\section{FILTERED EMG}

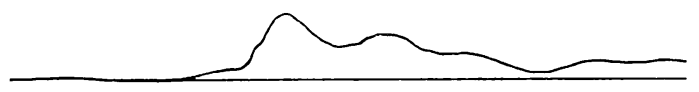

\section{EMG}

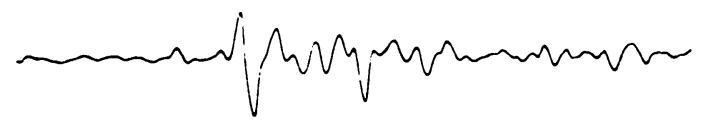

Fig. 2 Attempted movement of right arm. At time shown by arrow, the agonist muscles contract, but movement is blocked artificially. Position of arm does not change, and only a slight ripple occurs on velocity trace. Burst of EMG activity in antagonist muscle is smaller than burst seen in Figure 1. Duration of trace equals one second.

present study concerns the neural mechanism that brings about this contraction of the antagonist muscle.

Three mechanisms can be proposed. First, the antagonist could be activated by a central 'motor programme', defined as 'a set of muscle commands that are structured before a movement sequence begins, and that allows the entire sequence to be carried out uninfluenced by peripheral feedback' (Keele, 1968). Alternatively, it could be produced by segmental or 'long-loop' reflexes. Finally, it could result from interaction of a motor programme with afferent impulses from the moving limb.

Several observations tend to support the 'motor programme' hypothesis. The burst of EMG activity in the antagonist muscle begins very early in the course of a movement, often before the agonist has ceased firing. (This point is illustrated in the records published by Hallett et al., 1975.) If the extremity has not started to move, or has moved very little, when the antagonist begins to fire, it seems unlikely that the firing is caused by feedback from the periphery. Other arguments based on the timing and velocity of ballistic movements point to the same conclusion (Stetson and McGill, 1923; Bouisset and Lestienne, 1974).

Hallett et al. (1975) have recently published additional evidence for the concept of preprogramming. They reported that the firing patterns of agonist and antagonist muscles were normal in a patient whose limbs were essentially denervated by a pan-sensory neuropathy. In normal subjects, they found that an attempt to flex the elbow is accompanied by the usual burst of activity in triceps, even when the elbow is extended passively. Since the triceps activity occurred in the absence of the intended elbow movement, the authors inferred that it must be part of a central motor programme, not particularly subject to segmental influence.

The results of the present study do not support this conclusion. If the braking contraction is preprogrammed, it should not be affected by an unexpected change of the loading conditions. On the other hand, if it is modulated by proprioceptive inputs, one might expect a smaller burst of

Table Size of antagonist EMG $(\mathrm{mm})$

\begin{tabular}{|c|c|c|c|c|c|c|c|}
\hline \multirow[b]{2}{*}{ Subject } & \multirow[b]{2}{*}{$\begin{array}{l}\text { Initial Moves } \\
M\end{array}$} & \multirow[b]{2}{*}{$S D$} & \multicolumn{5}{|c|}{ Mixed blocked and unblocked moves } \\
\hline & & & $\begin{array}{l}\text { Unblocked } \\
M\end{array}$ & $S D$ & $\begin{array}{l}\text { Blocked } \\
M\end{array}$ & $S D$ & $P^{*}$ \\
\hline 1 & 28.40 & 6.71 & 25.24 & 5.93 & 13.48 & 6.84 & $<0.01$ \\
\hline 2 & 33.80 & 9.90 & 32.75 & 9.70 & 18.53 & 9.75 & $<0.01$ \\
\hline 3 & 23.84 & 7.39 & 24.14 & 6.35 & 9.39 & 5.79 & $<0.01$ \\
\hline 4 & 29.30 & 4.08 & 16.80 & 7.70 & 7.50 & 5.27 & $<0.01$ \\
\hline 5 & 25.67 & 7.77 & 27.09 & 10.60 & 14.48 & 8.14 & $<0.01$ \\
\hline 6 & 43.19 & 5.95 & 29.00 & 8.59 & 7.60 & 6.26 & $<0.01$ \\
\hline 7 & 36.69 & 7.25 & 34.00 & 8.74 & 11.84 & 6.8 & $<0.01$ \\
\hline
\end{tabular}

*Probability of the null hypothesis by $t$ test. 
activity when movement is prevented altogether. That expectation was confirmed by the present study. On trials in which no movement was allowed to occur, the antagonist muscle was often silent, and the mean amplitude of the EMG volley was reduced significantly for every subject. Hence, the results indicate that the contraction is affected by feedback from the limb. From the present data, one cannot determine whether this feedback operates through segmental reflexes, 'long-loop' reflexes (Phillips, 1969; Evarts, 1973) or a cerebellar assisted cortical servo-control (Conrad et al., 1974).

Of the three possible mechanisms listed above, the most likely appears to be the third: that the normal EMG pattern results from interaction of a central programme with feedback from the periphery. The initiation of EMG activity in the antagonist, which sometimes precedes the onset of movement, is best explained in terms of a central motor programme, but the duration and amplitude of this activity appear to be modulated by events at the periphery.

This interpretation agrees with the fact that a certain amount of EMG was recorded on trials in which no movement was allowed. One may postulate that, on such trials, contraction was initiated by a central programme, then stopped in response to proprioceptive feedback (or lack of feedback) from the stationary limb. Central preprogramming would thus provide the advantage of a very rapid response, and the segmental input would permit a prompt adjustment to loading conditions.

\section{References}

Angel, R. W. (1974). Electromyography during voluntary movement: The two-burst pattern. Electroencephalography and Clinical Neurophysiology, 36, 493-498.

Bizzi, E., Kalil, R. E., and Tagliasco, V. (1971). Eyehead coordination in monkeys: Evidence for centrally patterned organization. Science, 173, 452454.

Bouisset, S., and Lestienne, F. (1974). The organization of a simple voluntary movement as analysed from its kinematic properties. Brain Research, 71, 327-335.

Conrad, B., Matsunami, K., Meyer-Lohmann, J., Weisendanger, M., and Brooks, V. G. (1974). Cortical load compensation during voluntary elbow movements. Brain Research, 71, 504-514.

Evarts, E. V. (1973). Motor cortex reflexes associated with learned movement. Science, 179, 501-503.

Garland, H.., and Angel, R. W. (1971). Spinal and supraspinal factors in voluntary movement. Experimental Neurology, 33, 343-350.

Garland, H., Angel, R. W., and Melen, R. D. (1972). A state variable averaging filter for electromyogram processing. Medical and Biological Engineering, 10, 559-560.

Hallett, M., Adam, J., and Marsden, C. D. (1976). Ballistic movements in man. In International Symposium on Human Reflexes and Motor Disorders. Brussels, 21-23 April, 1976. Edited by J. E. Desmedt.

Hallett, M., Shahani, B. T., and Young, E. R. (1975). EMG analysis of stereotyped voluntary movements in man. Journal of Neurology, Neurosurgery, and Psychiatry, 38, 1154-1162.

Keele, S. W. (1968). Movement control in skilled motor performance. Psychological Bulletin, 70, 387-403.

Phillips, C. G. (1969). Motor apparatus of the baboon's hand. Proceedings of the Royal Society, London, Series $B, 173,141-174$.

Stetson, R. H., and McGill, J. A. (1923). Mechanisms of the different types of movements. Psychological Monographs, 32, 18-45.

Terzuolo, C. A., Soechting, J. F., and Palminteri, R. (1973). Studies on the control of some simple motor tasks. III. Comparison of the EMG pattern during ballistically initiated movements in man and squirrel monkey. Brain Research, 62, 242-246.

Wachholder, K., and Altenburger, H. (1926a). Beiträge zur Physiologie der willkürlichen Bewegung. IX. Mitteilung. Fortlaufende Hin- und Herbewegungen. Pflüger's Archiv für die gesamte Physiologie des Menschen und der Tiere, 214, 625-641.

Wachholder, K., and Altenburger, H. (1926b). Beiträge zur Physiologie der willkürlichen Bewegung. X. Mitteilung. Einzelbewegungen. Pflüger's Archiv für die gesamte Physiologie des Menschen und der Tiere, 214, 642-661.

Wachholder, K. (1928). Willkürliche Haltung und Bewegung insbesondere im Lichte electrophysiologischer Untersuchungen. Ergebnisse der Physiologie, 26, 568-775. 